\title{
ИССЛЕДОВАНИЕ НАДПОРШНЕВЫХ ЗАЗОРОВ АВТОТРАКТОРНЫХ ДИЗЕЛЬНЫХ ДВИГАТЕЛЕЙ
}

\section{Б.С. Антропов (фото)}

д.Т.Н., профессор, профессор кафедры автомобильного транспорта

ФГБОУ ВО «Ярославский государственный технический университет», г. Ярославль

\section{А.А. Рудаков}

преподаватель кафедры тактики и общевоенных дисциплин С.Ю. Салов

преподаватель кафедры тактики и общевоенных дисциплин «Ярославское высшее военное училище противовоздушной обороны», г. Ярославль

\section{Зазор, поршень, гильза, шатун, прокладка} газового стыка

Clearance, piston, sleeve, connecting rod, gas-tight joint gasket

\section{Е.А. Чернолихов}

студент

ФГБОУ ВО «Ярославский государственный технический университет», г. Ярославль

Надпоршневой зазор - зазор между днищем поршня, когда он находится в верхней мёртвой точке (ВМТ), и огневой поверхностью головки блока цилиндров, как это показано на рисунке 1.

На современных дизельных двигателях надпоршневой зазор $(\Delta)$ находится в пределах 0,9...1,35 мм, при этом каждая модель двигателя имеет свои пределы его изменения, что определяется особенностями конструкции ДВС. Указанный зазор влияет на топливную экономичность двигателя и дымность выпускных газов. Чем меньше его значение, тем меньше его влияние на указанные показате-

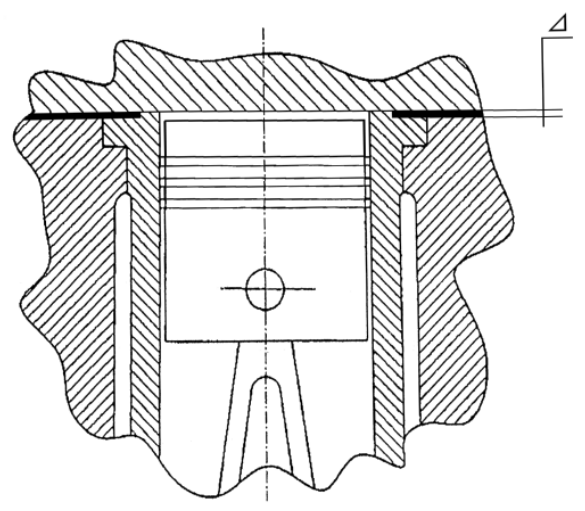

Рисунок 1 - Схема надпоршневого зазора $(\Delta)$ 
ли двигателя. Однако минимальное значение $\Delta$ ограничено образованием нагароотложений на поршне и головке блока цилиндров, что приводит к соударению этих деталей и появлению стука в двигателе. Данная особенность характерна для длительной работы на режимах холостого хода.

Увеличение максимального значения, оптимального для каждой модели двигателя, приводит к ухудшению его показателей работы. Так, исследованиями в экспериментальном цехе Ярославского моторного завода, входящего в состав ОАО «Автодизель», доказано, что увеличение $\Delta$ на каждую 0,1 мм от оптимального значения приводит к увеличению удельного расхода топлива (в среднем на 1,5 г/л.с.ч.) и дымности отработанных газов (на 5,0 единиц (или процентов)).

С учётом важности надпоршневого зазора, на современных автомобильных дизельных двигателях внедрены мероприятия, обеспечивающие его оптимальные значения при сборке на заводах-изготовителях.

На отечественных дизельных двигателях впервые мероприятия по ограничению надпоршневого зазора были внедрены на двигателях КамАЗ, для которых $\Delta=0,92 \ldots 1,27$ мм. Надпоршневой зазор на этих двигателях выдерживается следующим образом [1].

На двигателях с установленным коленчатым валом в блоке и гильзами цилиндров (при сборке) определяется расстояние «A», как это показано на рисунке 2.

В зависимости от размера «A» на нерабочем торце гильзы выбиваются индексы 10, 20, 30 и 40.

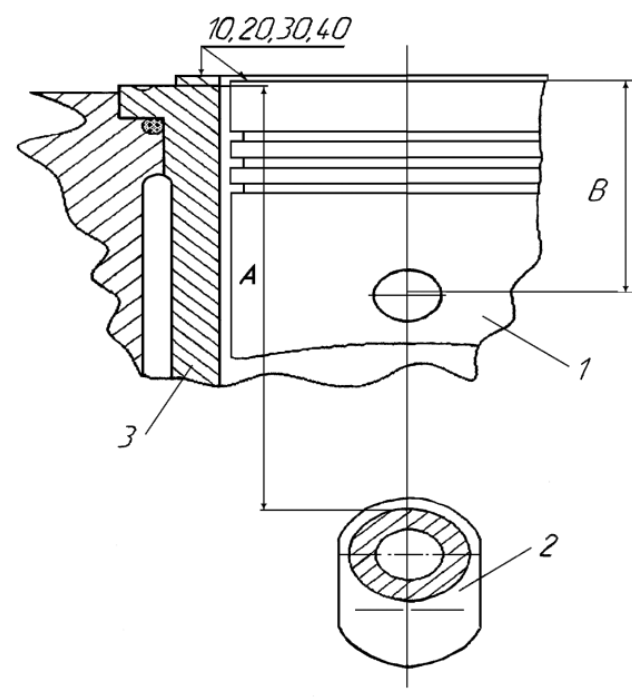

1 - поршень; 2 - коленчатый вал; 3 - гильза.

Рисунок 2 - Схема замера размеров «A» и «B»
Указанные работы выполняются автоматически по мере движения деталей на сборочном конвейере.

Поршни при их контроле после изготовления также разбиваются на группы в зависимости от размера «В», показанного на рисунке 2. В зависимости от значения размера «B» на днище поршня выбиваются индексы 10, 20, 30 и 40. Таким образом, детали цилиндро-поршневой группы (ЦПГ) двигателей КамАЗ по значению надпоршневого зазора разбиваются на 4 группы и имеют обозначения 10, 20, 30. 40. Детали ЦПГ двигателей КамАЗ не имеют разбивки по значению диаметрального зазора «поршень - гильза», который у них постоянен и обеспечивается высокой точностью изготовления деталей.

Разбивка гильз и поршней на двигателях КамАЗ производится согласно размерам «А» и «B», указанным в таблице 1.

Размер «А» представляет собой расстояние от образующей шатунной шейки коленчатого вала в верхнем положении (положение поршня в BMT) до рабочего бурта гильзы, с помощью которого и стальной прокладки обеспечивается герметичность камеры сгорания.

Размер «В» есть расстояние от оси отверстия в поршне под палец до днища поршня.

Когда на конвейере блок цилиндров поступает на участок, где устанавливаются шатуны в сборе с поршнями, то по индексу гильз определяются шатуны в сборе с поршнями, т.е. если гильзы имеют индекс 10, то поршни вместе с шатунами необходимы с индексом 10 и т.д. При такой сборке надпоршневой зазор в цилиндрах двигателя будет оптимальным: $\Delta=0,92 . .1,27$ мм.

Как следует из таблицы 1, по мере увеличения номера индекса (при переходе от предыдущей группы к следующей) происходит увеличение размера «A» на 0,11 мм.

Аналогичным образом увеличивается размер «В» поршней, т.е. поршень с индексом 10 - самый короткий, а с индексом 40 - самый длинный.

Индекс гильзы определяется не только высотой рабочего бурта, но и глубиной расточки в блоке под этот бурт, а также расположением коленчатого вала в коренных опорах. В связи с этим гильза как бы «привязана» к блоку цилиндров конкретного двигателя. Поэтому при замене гильзы в условиях автотранспортного предприятия (АТП) индекс, установленный на ней, теряет всякое значение. При постановке новой гильзы в блок цилиндров изменяется размер «A». Учитывая это обстоятельство, в запасные части 
Таблица 1 - Значения размеров «A» и «В» для гильз и поршней при разбивке их на группы

\begin{tabular}{|c|c|c|}
\hline Размер « $A »$, мм & Индекс гильзы и поршня & Размер «B», мм \\
\hline от 260,13 до 260,24 & 10 & от 75,67 до 75,78 \\
\hline от 260,24 до 260,35 & 20 & от 75,78 до 75,89 \\
\hline от 260,35 до 260,46 & 30 & от 75,89 до 75,90 \\
\hline от 260,46 до 260,47 & 40 & от 75,90 до 76,01 \\
\hline
\end{tabular}

заводом-изготовителем должны поставляться гильзы, не имеющие индексов. Поршни в запасные части должны поставляться с индексом 10. Это исключает возможное соударение поршней с огневой поверхностью головки цилиндров и проявления стука при работе двигателя при минимальной частоте вращения коленчатого вала.

Ha двигателях ЯM3 размерности S/D = 140/140 мм, выпускаемых мелкими сериями на Ярославском моторном заводе, надпоршневой зазор обеспечивается в оптимальных пределах $\Delta=0,94 \ldots 1,35$ мм путём подбора стальной прокладки газового стыка (рис. 3) [2]. Рассматриваемые двигатели ЯМ3-840 и их модификации являются V-образными, 12-цилиндровыми, с номинальной мощностью 400...588 кВт (550...800 л.с). Двигатели имеют индивидуальные головки цилиндров.

В зависимости от выступания поршня в положении ВМТ относительно рабочего бурта гильзы (размер «А») определяется вариант стальной прокладки (рис. 4).

Применяются стальные прокладки трёх вариантов по толщине 1,$3 ; 1,5$ и 1,7 мм с индексом 10, 20 и 30 соответственно. Место нахождения индекса показано на рисунке 3.

Замер размера «А» производится в каждом цилиндре двигателя, в плоскости качания шатуна, в двух диаметрально расположенных точках (рис. 4). По результатам замеров размер «А» определяется как среднее значение. Пределы выступления бурта гильзы (изменения размера «А») и соответствующие им прокладки с индексом приведены в таблице 2.

Выступание гильзы над рабочим буртом замеряется индикатором. Гильза при этом устанавливается в расточку блока с уплотнительными кольцами (нижнего пояса и верхнего бурта) и зажимается двумя специальными прижимами.

Для обеспечения величины надпоршневого зазора в оптимальных пределах при демонтаже головки цилиндров стальную прокладку необ-

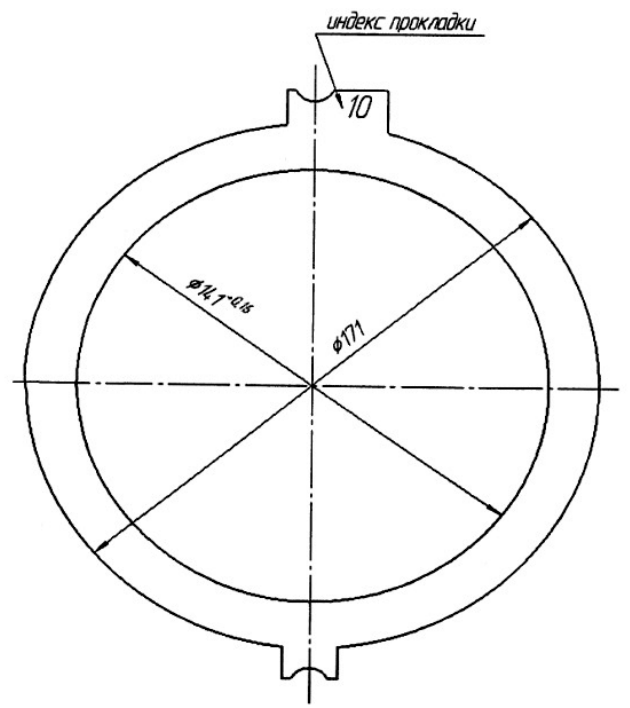

Рисунок 3 - Стальная прокладка газового стыка (размеры в мм)

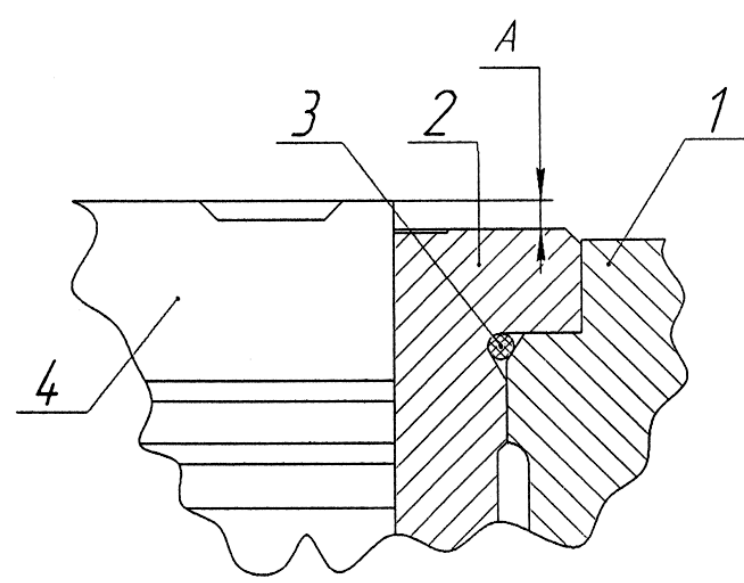

1 - блок цилиндров; 2 - гильза; 3 - верхнее кольцо уплотнения гильзы; 4 - поршень.

Рисунок 4 - Схема замера размера «A» 
Таблица 2 - Размеры и индексы стальных прокладок

\begin{tabular}{|c|c|c|}
\hline \multirow{2}{*}{$\begin{array}{c}\text { Выступание поршня над торцом } \\
\text { гильзы - «А», мм }\end{array}$} & \multicolumn{2}{|c|}{ Стальная прокладка } \\
\cline { 2 - 3 } & Толщина, мм & Индекс \\
\hline св. 0,05 до 0,25 & $1,3_{-0,05}$ & 20 \\
\hline св. 0,25 до 0,45 & $1,5_{-0,05}$ & 30 \\
\hline св. 0,45 до 0,65 & $1,7_{-0,05}$ & \\
\hline
\end{tabular}

ходимо установить в том же положении и на тот же цилиндр, откуда она была снята. При замене индивидуальной головки цилиндров, а также при нарушении положения гильзы от первоначального, в расточке блока необходимо заменить стальную прокладку на новую. В запасные части заводом-изготовителем должны поставляться только прокладки с индексом 30, т.е. наибольшие по толщине, с целью исключения соударения поршня с огневой поверхностью головки цилиндров при сборке в условиях АТП.

Известны и другие методы обеспечения оптимального надпоршневого зазора на автомобильных дизелях. Так, на двигателях Заволжского моторного завода серии 3М3-51432, предназначенных для автомобилей УАЗ, в том числе для внедорожников «Патриот», надпоршневой зазор регулируется с помощью шатунных вкладышей, которые являются разностенными и взаимозаменяемыми [3]. На указанных двигателях (двигатели рядные, 4-цилиндровые, S/D = 94/87 мм, номинальная мощность 83,5 кВт/113,5 л.с.) при сборке замеряется расстояние от рабочего бурта гильзы до днища поршня в ВMT, при установленных в шатун верхних «тонких» вкладышах. Если этот размер находится в норме, т.е. обеспечивает оптимальное значение надпоршневого зазора, то двигатель собирается далее. Если размер более нормы, то нижние «толстые» вкладыши меняются местами с верхними «тонкими» (рис. 5).

На ряде двигателей иностранного производства надпоршневой зазор в оптимальных пределах обеспечивается путём разбивки поршней и шатунов на группы, которые маркируются индексами 10 и 20.

Поршни разбиваются на группы также как на двигателях КамАЗ, т.е. по расстоянию «В» (рис. 2). Шатуны разбиваются по размеру «А», представляющему собой межцентровое расстояние между расточками верхней и нижней головок шатуна, как показано на рисунке 6.

Комплектование поршней и шатунов производится по одному и тому же индексу. Вполне

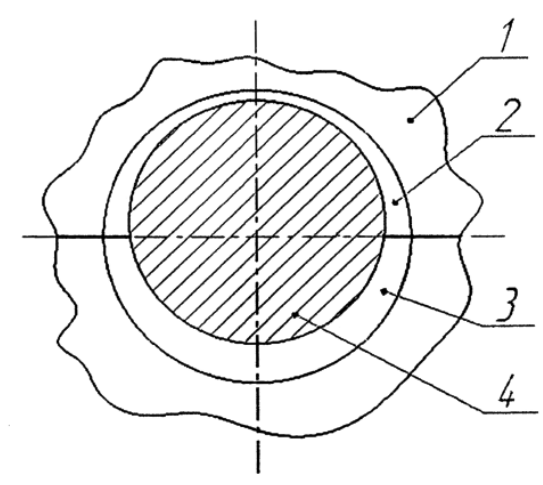

1 - расточка нижней головки шатуна; 2 - верхний вкладыш; 3 - нижний вкладыш; 4 - шатунная шейка коленчатого вала.

Рисунок 5 - Схема установки шатунных вкладышей при регулировке надпоршневого зазора

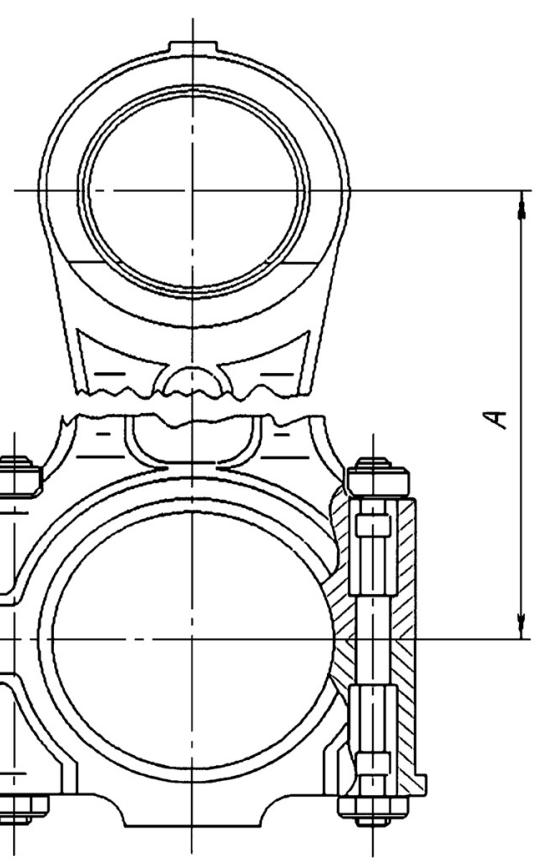

Рисунок 6 - Шатун в сборе 
очевидно, что комплект указанных деталей с индексом 10 - «короткий» и 20 - «длинный».

На участке конвейера, где в блок цилиндров устанавливаются указанные комплекты, осуществляется замер расстояния от привалочной поверхности блока цилиндров до образующей шатунной шейки коленчатого вала, находящейся в верхнем положении. В зависимости от этого расстояния устанавливаются комплекты с индексом 10 или 20. Тем самым выдерживается оптимальный надпоршневой зазор на двигателях. Указанные индексы нанесены на днище поршней (аналогично двигателям КамАЗ) и на боковой поверхности шатунов, как это показано стрелкой «B» на рисунке 6. Двигатели с такой разбивкой на группы деталей имеют общую головку блока цилиндров и стальную прокладку под ней.

\section{Вывод}

Установлено, что надпоршневой зазор в дизельных двигателях составляет 0,9...1,35 мм. Он обеспечивается: разбивкой гильз и поршней на группы; применением стальных прокладок газового стыка, различных по ширине; установкой разностенных вкладышей в шатуны двигателей. Оптимальный зазор обеспечивает топливно-экономические и экологические показатели автомобиля в эксплуатации, гарантируемые заводом-изготовителем.

Материал, изложенный в статье, по мнению авторов, представляет интерес для инженернотехнических работников, занятых в сфере эксплуатации автотранспортной техники, а также может быть использован в учебном процессе при подготовке специалистов по эксплуатации, обслуживанию и ремонту указанной техники.

\section{Лumepamypa}

1. Приспособление для замера надпоршневого зазора [Электронный ресурс]. - Режим доступа: http:// www.ideasandmoney.ru/Ntrr/Details/115105.

2. Антропов, Б.С. Новые автотракторные двигатели ЯМЗ [Текст]: учебное пособие / Б.С. Антропов, Г.М. Савельев. - Ярославль: ЯИПКиПК, 1992. - 112 с. 2006.

3. Руководство по эксплуатации дизельного двигателя 3М3 51432.10 [Текст]. - 2-е изд. - Заволжье,

\section{References}

1. Prisposoblenie dlja zamera nadporshnevogo zazora [Jelektronnyj resurs]. - Rezhim dostupa: http://www. ideasandmoney.ru/Ntrr/Details/115105.

2. Antropov, B.S. Novye avtotraktornye dvigateli JaMZ [Tekst]: uchebnoe posobie / B.S. Antropov, G.M. Savel'ev. - Jaroslavl': JalPKiPK, 1992. - 112 s.

3. Rukovodstvo po jekspluatacii dizel'nogo dvigatelja ZMZ 51432.10 [Tekst]. - 2-e izd. - Zavolzhye, 2006.

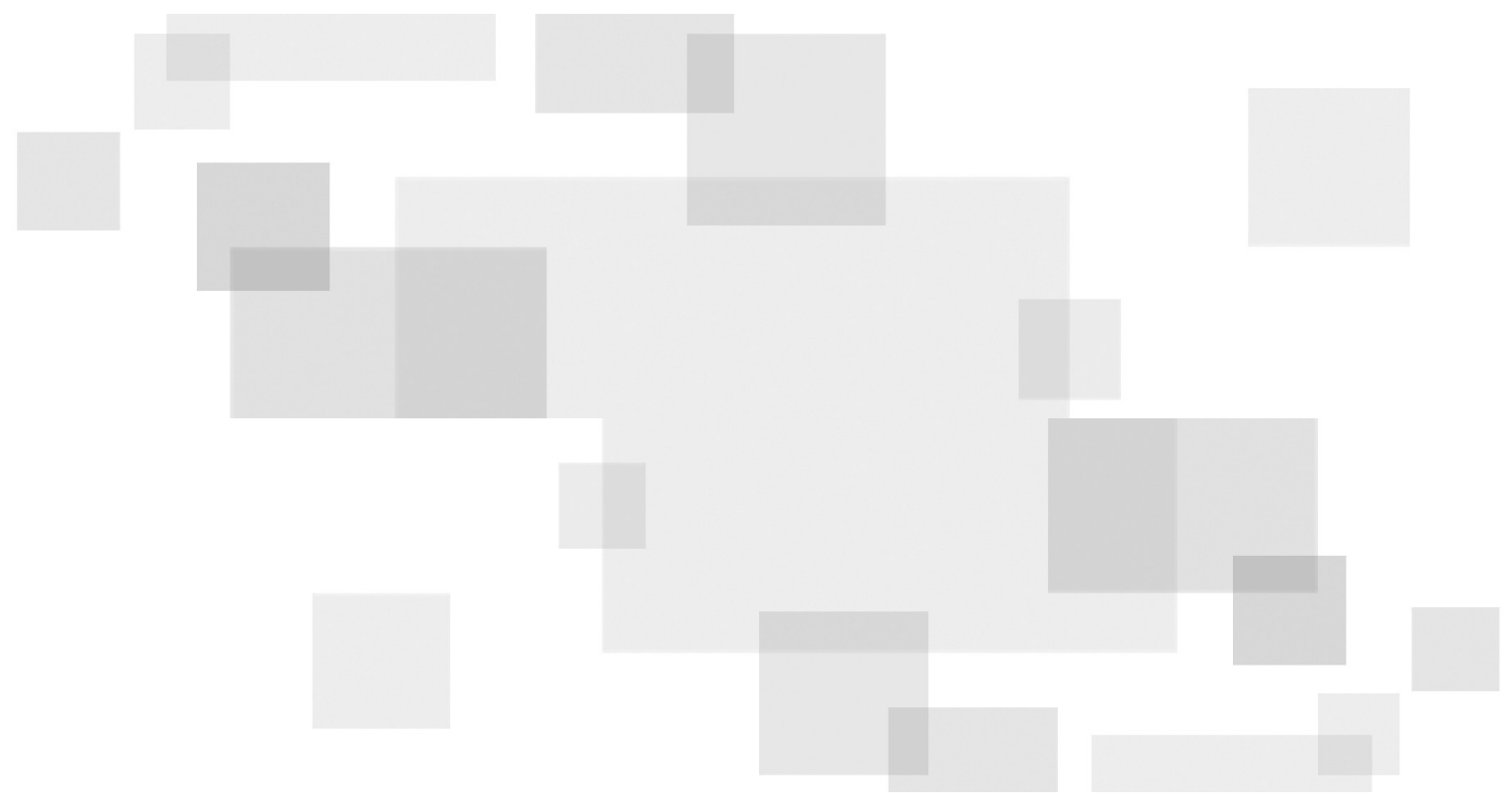

